\title{
A study of the latitudinal dependence of the quasi-biennial oscillation in Total Ozone Mapping Spectrometer total ozone
}

\author{
By E. ECHER ${ }^{1 *}$, F. L. GUARNIERI ${ }^{1,2}$, N. R. RIGOZO ${ }^{1,3}$ and L. E. A VIEIRA ${ }^{1},{ }^{1}$ Instituto \\ Nacional de Pesquisas Espaciais (INPE), Av. Astronautas 1758, 12201-970, São José dos Campos, SP, Brazil; ${ }^{2}$ Jet \\ Propulsion Laboratory, 4800 Oak Grove Drive, Pasadena, CA 91109-8099, USA $;{ }^{3}$ Faculdade de Tecnologia Thereza \\ Porto Marques, FAETEC, Jacareí, SP, Brazil
}

(Manuscript received 21 October 2003; in final form 19 May 2004)

\begin{abstract}
A wavelet multiresolution analysis of the quasi-biennial oscillation (QBO) latitudinal structure in total ozone is performed for the period 1979-1992 (Nimbus-7 TOMS data). It has been found that ozone is nearly in phase with the QBO signal in the equatorial region $\left(0^{\circ}-5^{\circ}\right.$ and $\left.5^{\circ}-10^{\circ}\right)$, and it is out of phase (lag $\sim+15$ and -15 months in north and south) in the $10^{\circ}-15^{\circ}$ to $55^{\circ}-60^{\circ}$ latitudinal bands. The cross-correlation coefficient between total ozone and zonal wind index is high $(>0.7)$ at latitudes lower than $10^{\circ}$, decreases in the transition region $10^{\circ}-15^{\circ}(r \sim 0.4)$ and it has a non-linear profile at high latitudes, with a maximum near the $25^{\circ}-30^{\circ}$ band. The correlation is observed to be higher in the Southern Hemisphere latitudinal bands. Spectral analysis was performed for each latitudinal range, and QBO period and amplitude profiles were obtained. A detailed latitudinal profile of the QBO signal in total ozone is obtained from the present analysis.
\end{abstract}

\section{Introduction}

The quasi-biennial oscillation (QBO) in the equatorial stratospheric zonal winds is one of the most prominent features of stratospheric equatorial circulation, characterized by alternate easterly and westerly phases in the zonal wind, with average periods of 27-28 months, ranging over 22-34 months and with maximum amplitude between $70-10 \mathrm{hPa}$. This oscillation influences not only the wind and thermal structure at the equator, but also the stratospheric warming and the transport of trace gases, such as ozone, to polar regions (Shepherd, 2000). The QBO was discovered more than four decades ago (Reed et al., 1961; Veryard and Ebdon, 1961). It is quantified by a zonal wind index (ZWI), obtained from wind measurements in the lower stratosphere at equatorial locations (Naujokat, 1986).

The quasi-biennial variation in total ozone was first reported by Funk and Garnham (1962), as related to the zonal stratospheric wind QBO (Reed et al., 1961). The QBO in ozone at middle and high latitudes was discovered soon afterward (Angell and Korshover, 1973). The phase between total ozone and zonal wind is latitude-dependent, ozone being in phase with

\footnotetext{
*Corresponding author. e-mail: eecher@dge.inpe.br
}

the zonal wind at equatorial regions and out of phase in extratropical latitudes (Hilsenrath and Schlesinger, 1981; Zerefos et al., 1992, 2001; Hollandsworth et al., 1995; Kane et al., 1998).

The alternately descending westward and eastward winds are probably driven by absorption in the stratosphere of vertically propagating equatorial Kelvin and Rossby gravity waves generated in the troposphere (Holton and Lindzen, 1972). This wave driving of zonal flow also produces a secondary mean-meridional circulation in the latitude-height plane, with descending motion along the equator during periods of westerly shear and ascending motions during periods of easterly shear motion (Plumb and Bell, 1982). When the equatorial zonal wind is in its westerly shear phase, close to the equator there is subsidence from the higher regions (above about $28 \mathrm{~km}$ ) into the $30-50 \mathrm{hPa}$ layer, induced by a maximum diabatic cooling due to the warmest phase of the temperature QBO on the equator. Below about 28 $\mathrm{km}$ the ozone chemical lifetime is relatively long compared with dynamical processes, while above $28 \mathrm{~km}$ its chemical lifetime is very short. Thus, the relative descent of air through this region produces an increase in the total column of ozone, because at levels above $28 \mathrm{~km}$ ozone is replaced by chemical production on relatively short time-scales. At the same time, and by the same mechanism, enhanced upwelling from the 30-50 hPa layer (and subsidence below it) occurs over the subtropical latitudes, 
producing a total ozone deficit there. During the easterly shear motion of equatorial winds, the process is reversed and results in an ozone increase over the subtropics and an ozone decrease over the equatorial zone (Funk and Garnham, 1962; Angell and Korshover, 1973; Hasebe, 1980, 1983; Oltmans and London, 1982). This simple mechanism explains a large component of the ozone QBO variation, but there are probably other factors operating.

Actually, changes in the stratospheric transport processes between the equator and the subtropics do not occur instantaneously, and a distance-dependent time lag results between the start and the termination of the total ozone deviations observed in the subtropics. For example, when a stratospheric westerly maximum is reached above the equator, the subsidence over the tropics continues for another eight to nine months, causing relative ozone increases there (Zerefos et al., 1992).

The cause of QBO in ozone outside the equatorial region seems controversial. The hypotheses are as follows. (i) The equatorial QBO circulation could extend to higher latitudes. (ii) The seasonally varying mean-meridional circulation might transport the equatorial QBO in ozone anomalies to the subtropics, but, if this were the case, the extratropical QBO would have the same characteristics as the equatorial QBO. (iii) A combination of the two mechanisms above: the equatorial QBO would have a subtropical branch, out of phase with the equatorial branch, which could be carried to higher latitudes by the climatologic mean and eddy circulation (Gray and Pyle, 1989).

Latitude dependence of the QBO in total ozone is analyzed in this work. Nimbus7-TOMS ozone data during 1979-1992 were decomposed in orthonormal frequency levels using the Meyer wavelet transform. The level corresponding to the QBO signal was analyzed through correlation, cross-correlation and spectral analysis techniques. Echer (2004) previously performed a multiresolution analysis of the global ozone data. This work is a more complete and detailed analysis of the QBO signal in ozone, using zonal means over all longitudes with a bandwidth of $5^{\circ}$, and employing a relatively new signal analysis tool, the wavelet transform.

\section{Zonal wind and ozone data}

The ZWI is derived from a concatenation of stratospheric wind data at Canton Island $\left(3^{\circ} \mathrm{S}, 172^{\circ} \mathrm{W}\right)$ for January 1953 to August 1967, at Gan, Maldive Island ( $\left.1^{\circ} \mathrm{S}, 7^{\circ} \mathrm{E}\right)$ for September 1967 to December 1975 , and at Singapore $\left(1^{\circ} \mathrm{N}, 104^{\circ} \mathrm{E}\right)$ for January 1986 onwards (Naujokat, 1986). The QBO ZWI at $30 \mathrm{hPa}$ (ZWI) used in this study was obtained from the Frei Universität Berlin homepage (http://strat-www.met.fu-berlin.de/). The ZWI is then a merged series of zonal wind velocity at $30 \mathrm{hPa}$ and it is measured in $\mathrm{m} \mathrm{s}^{-1}$.

Global total ozone was measured by the Total Ozone Mapping Spectrometer (TOMS) instrument on board Nimbus-7 from October 31, 1978 to May 6, 1993 (Stanford et al., 1995). In this work, zonal mean averages of the version 7 Nimbus 7 data were used during 1979-1992. These zonal means are $5^{\circ}$ latitude band average ozone. Data were selected during 1979-1992 and for the latitudinal range $60^{\circ} \mathrm{S}-60^{\circ} \mathrm{N}$. Ozone data from latitudes higher than $60^{\circ}$ were not used because of the polar night; TOMS needs the scattered solar light to measure ozone, and data from these latitudes are not available for the whole year (Stolarski et al., 1991). The areal coverage is $90 \%$ of the globe, and excludes the ozone hole region; this coverage is adequate to study the extratropical QBO. Total ozone data were obtained from the TOMS homepage (http://jwocky.gsfc.nasa.gov/). The period 1979-1992 was chosen because it is a continuous ozone data base, from the same satellite instrument. Wavelet analysis needs such continuous data, and because ozone satellite data had a gap during the years 1995-1996, later data could not be used in the present analysis.

\section{Wavelet and spectral analysis}

The wavelet transform is a very powerful tool to analyze non-stationary signals and to obtain signal expansions using time-localized functions - wavelets that have good properties of localization in time and in frequency domains (Kumar and Foufoula-Georgiou, 1997; Percival and Walden, 2000). The wavelet transform may be continuous or discrete. While the continuous wavelet transform calculates coefficients at every possible scale, the discrete wavelet transform chooses scales and positions based on a power of two - the dyadic scales and positions. Thus, the discrete wavelet is a subsampling of the continuous one at just the dyadic scales $2^{j-1}, j=1,2 \ldots$.

The discrete wavelet transform may be used in multiresolution analysis, which is concerned with the study of signals or processes represented at different resolutions and with developing an efficient mechanism for going from one resolution to another (Percival and Walden, 2000). Wavelet transform is based on reducing signals to their components by using a set of basis functions. Wavelet basis functions are related to each other by simple scaling and translation. The original wavelet function, the mother wavelet, is used to generate all the other basis functions.

In the multiresolution (or multiple level) decomposition, a signal $(S)$ is broken down iteratively into many lower-resolution components. This decomposition process, with successive approximations being decomposed in turn, is called the wavelet decomposition tree. A signal $(S)$ is split into an approximation $(A)$ and a detail $(D)$. The detail contains the high-frequency part of the signal, whereas the approximation contains most of the characteristic frequencies of the signal. In the first step of the decomposition, $S=A_{1}+D_{1}$. In a next step, the approximation itself is split into a second level approximation, $A_{1}=A_{2}+D_{2}$, and $S=A_{2}+D_{2}+D_{1}$, and so on. The process is equivalent to a filtering procedure; in the first step, the signal has a low-pass filtered component, the $A_{1}$, and a high-pass filtered component, the $D_{1}$ level. $A_{1}$ is then itself split, and one has the $D_{2}$ level 
as bandpass filtered data (because higher frequencies were split into the $D_{1}$ level and lower frequencies into the $A_{2}$ level).

This iterative process could, in theory, continue indefinitely. In reality, the decomposition can proceed only until the individual details consist of a single sample or proxy. In practice, the most suitable decomposition of a given signal is selected on an entropy-based criterion or depending on the nature of the signal (Percival and Walden, 2000).

Based on several characteristics of the wavelet functions, it is possible to determine which wavelet is more suitable for a given application. The Meyer wavelet transform is an orthonormal transform, and it has a scaling function besides the wavelet function, which is necessary for multiresolution analysis. The wavelet is determined by the high-pass filter, producing the details of the wavelet decomposition, while the scaling function, which is very similar to the wavelet function, is determined by the low-pass filter and it is associated with the approximations of the wavelet decomposition. Because in multiresolution analysis a signal is split into its approximations and details, both the wavelet and scaling function are needed. This is enough information to decompose a signal into orthonormal frequency levels (Percival and Walden, 2000; Echer, 2004). The Meyer wavelet transformed data are then decomposed in orthonormal frequency levels, but the upper and lower frequencies are limited only to the dyadic values $2^{j}-2^{j+1}$. This method is very good at isolating signals within these limits with low contamination from signals outside the band (Echer, 2004).

In order to identify the main periodicities, their amplitude and phase in each wavelet decomposition level, an iterative multiple regression model (Wolberg, 1967), labeled ARIST (Iterative Regression Analysis of Time Series; Rigozo and Nordemann, 1998), was used. This method can be applied to fit any function, by iteratively calculating the coefficients of the particular function. In the search for periodicities in time series, a sine function is used for each period, with three unknown parameters: amplitude, frequency and phase. The starting point of the method is to define the conditional function

$F=Y-r_{n} \sin \left(w_{n} t+\phi_{n}\right)$

where $Y$ is the observed signal, and $r_{n}, w_{n}$ and $\phi_{n}$ are amplitude, frequency and phase, respectively, of the $n$th periodicity. $F$ is the conditional function, that represents the difference between the measured value $Y$ and the fit curve for the corresponding abscissa. Because the method is iterative, in every step corrective terms are calculated. They will be applied to the parameters $r_{n}$, $w_{n}$ and $\phi_{n}$. Periodicities significant at approximately the $95 \%$ confidence level can be selected by considering periods with amplitude higher than two times the standard deviation of the spectral amplitude found by the method $\left(r_{n}>2 \sigma_{n}\right)$. ARIST is applied in this work only to the $D_{4}$ levels, and several waves are fit, but only the significant periodicities at $2 \sigma$ are selected for further analysis. The ARIST spectrum is composed by discrete lines, corresponding to the frequencies of the sine wave fits.
Cross-correlation analysis was performed between ZWI and ozone. In this case, a positive lag indicates ozone maximum after ZWI maximum and a negative lag indicates ozone maximum before ZWI maximum.

\section{Results and discussion}

Echer (2004) analyzed global total ozone variations in wavelet frequency bands and their dependency on solar activity, El Niño Southern Oscillation (ENSO) and QBO during the period 19791992. In that work, global ozone was decomposed to Meyer wavelet frequency bands and a detailed analysis was performed on each band. In the Meyer wavelet frequency $D_{4}$ level, which corresponds to 16-32 month bandpass filtered data, the crosscorrelation between ozone and ZWI resulted in $r=-0.81$, indicating an anticorrelated variation, as previously observed (Tung and Yang, 1994).

Only $D_{4}$ levels, which contain the QBO signal of each latitudinal band, are used in this work. In Figs. 1 and 2 ozone (solid line) and ZWI (dotted line) $D_{4}$ frequency levels are shown. Figure 1 shows $0^{\circ}-5^{\circ}$ to $30^{\circ}-35^{\circ}$ latitudinal bands, for the Southern (S) and Northern (N) Hemispheres on the left and on the right, respectively. Figure 2 shows the $35^{\circ}-40^{\circ}$ to $55^{\circ}-$ $60^{\circ}$ latitudinal bands, the $\mathrm{S}$ and $\mathrm{N}$ Hemispheres, and the globe levels.

From these figures, ozone and ZWI are seen to be in phase in the equatorial region, in the $0^{\circ}-5^{\circ} \mathrm{N}, 0^{\circ}-5^{\circ} \mathrm{S}, 5^{\circ} \mathrm{N}-10^{\circ} \mathrm{N}$ and $5^{\circ} \mathrm{S}-10^{\circ} \mathrm{S}$ bands in both hemispheres. Global and hemispheric ozone are observed to be anticorrelated to ZWI, as expected (Bowman, 1989; Yang and Tung, 1995; Kane et al., 1998). The QBO signal in ozone is clearly seen in the equatorial region (latitudes lower than $10^{\circ}$ ), where its pattern is simpler and in phase with the ZWI signal, while outside the equatorial belt, the signal is more complex, with more peaks indicating higherfrequency components, and it is out of phase with the ZWI signal.

Figure 3 shows the linear fit correlation coefficients (calculated at lag zero) between ozone (open triangles for the Northern Hemisphere and full circles for the Southern Hemisphere) and ZWI obtained using the data shown in Figs. 1 and 2. The correlations for the globe $(\mathrm{G})$, and total Northern $(\mathrm{N})$ and Southern (S) Hemispheres are also indicated to the side by asterisks $(*)$. Correlation coefficients are higher for the Southern Hemisphere than for the Northern Hemisphere, but the trend in the correlation coefficients is the same, for both hemispheres. Correlation is positive and very high $(r>0.8)$ only in the equatorial belt (latitudes lower than $10^{\circ}$ ). The globe and the Northern and Southern Hemispheres as a whole have negative correlations. From the $10^{\circ}-15^{\circ}$ to the $55^{\circ}-60^{\circ}$ latitudinal bands, the correlation is also negative. Correlation coefficients are small in the $10^{\circ}-15^{\circ}$ band, increasing to a secondary maximum (lower than the equatorial maximum) in the $20^{\circ}-25^{\circ}$ band and then starting to decrease in magnitude again. 

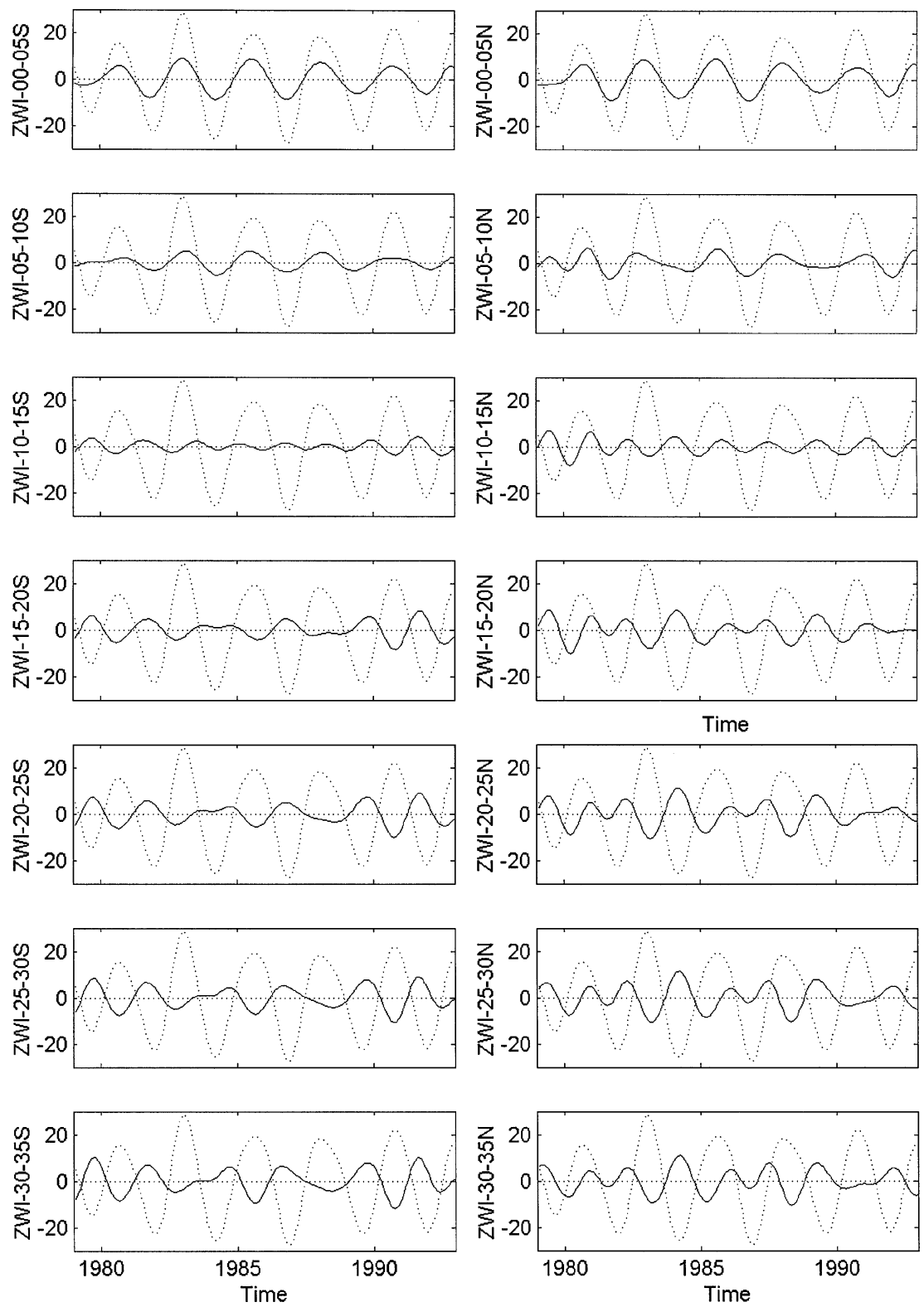

Fig 1. Ozone (solid line) and ZWI (dotted line) Meyer wavelet $D_{4}$ frequency levels. Ozone levels are the global, the whole Northern and Southern Hemispheres and northern latitude bands from the equator $\left(0^{\circ}-5^{\circ}\right)$ to high latitudes $\left(50^{\circ}-55^{\circ}\right)$.

Figure 4a shows the cross-correlation coefficients between ozone and ZWI (open triangles for the Northern Hemisphere and full circles for the Southern Hemisphere). These coefficients are different from the linear fit coefficients, because they are not determined at a zero lag, but at the lag where they are maximized. The correlation coefficients for the globe and the total Northern and Southern Hemispheres are again indicated with asterisks $(*)$. Similarly to the linear fit results (Fig. 3), coefficients are higher for the Southern Hemisphere than for the Northern Hemisphere, but the latitudinal profile is the same for both hemispheres. A non-linear profile is seen, with a main maximum followed by an abrupt minimum, a smooth increasing trend to a secondary maximum, and then a smooth decreasing trend. Coefficients are high $(r>0.90)$ in the $0^{\circ}-5^{\circ}$ and $5^{\circ}-10^{\circ} \mathrm{S}$ bands, and greater than 0.75 through $10^{\circ} \mathrm{N}$. The coefficient decreases to $0.35-0.45$ in the $10^{\circ}-15^{\circ}$ band, and increases again reaching a maximum in the $25^{\circ}-30^{\circ}$ band in both hemispheres. Onwards, correlations decrease with increasing latitude. The global coefficient is 0.78 , while for Southern and Northern Hemispheres it is 0.63 and 0.38 , respectively. These cross-correlation coefficients are similar to the values found by Kane et al. (1998), which were $r>0.7$ at the equator, $r \sim 0.3$ in the $5^{\circ}-15^{\circ}$ band and $r \sim 0.5$ for $15^{\circ}-45^{\circ}$ latitudes.

Lags are seen in Fig. 4b. Lag is negative for global $(-15$ months) and Southern Hemisphere ( -14 months) and positive for Northern Hemisphere total ozone (+14 months). Regarding latitudinal bands, ozone has a zero-year lag (in phase) with ZWI in $0^{\circ}-5^{\circ}$ and $5^{\circ}-10^{\circ}$ bands in both hemispheres. Lag from 
Fig 2. Ozone (solid line) and ZWI (dotted line) Meyer wavelet $\mathrm{D}_{4}$ frequency levels. Ozone levels are $55^{\circ}-60^{\circ}$ northern latitude band and the southern latitude bands from the equator $\left(0^{\circ}-5^{\circ}\right)$ to high latitudes $\left(55^{\circ}-60^{\circ}\right)$.
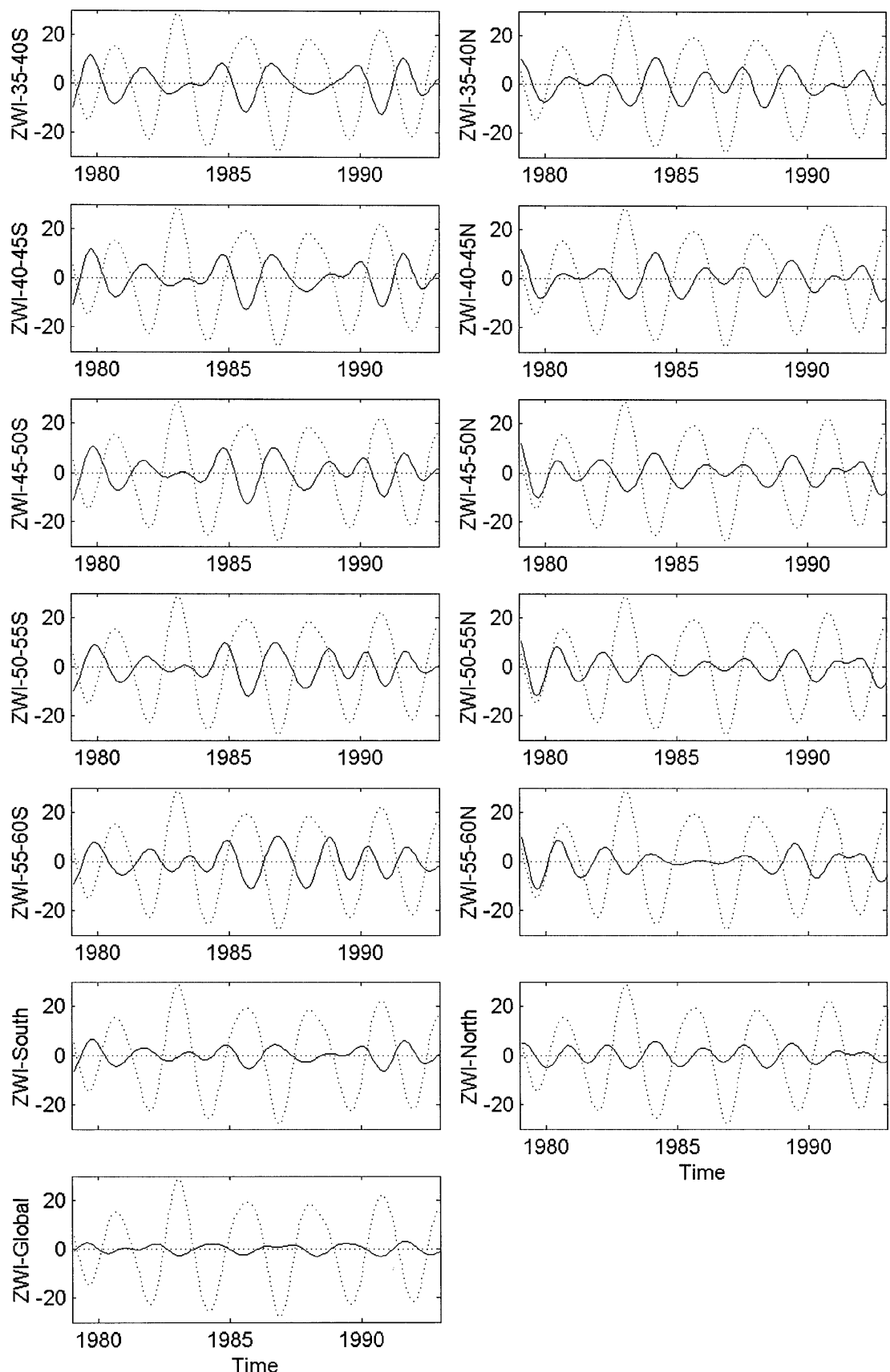

these latitudes onwards is prevailing negative (around $-14,-15$ months) in the Southern Hemisphere. For the Northern Hemisphere, lag is negative in $10^{\circ}-15^{\circ}$ to $15^{\circ}-20^{\circ}$ bands $(-18,-20$ months) and has a reversal of phase to positive values in the $20^{\circ}-25^{\circ}$ to $55^{\circ}-60^{\circ}$ bands $(+14,+15$ months $)$.

Most of the latitudinal bands, as well as the hemispheric averages, indicate that the ozone maximum occurs before the ZWI maximum in the Southern Hemisphere, but after the ZWI maximum in the Northern Hemisphere. However, it is important to notice that the lag of \pm 15 months is half a cycle of the QBO period ( $\sim 30$ months). Thus, a lag of $\sim 15$ months is the same as a lead of 15 months, and ozone is not out of phase between mid-latitudes of both hemispheres. The fact that Southern Hemisphere ozone leads the ZWI while Northern Hemisphere ozone lags the ZWI by half a cycle could have some physical significance, but probably it is an effect of minor variations in the filtered time series. For some latitudinal bands, the difference in the correlation coefficient shifting the time series forward half a cycle or back half a cycle relative to the ZWI was very small, but for other bands the difference was significant. Kane et al. 


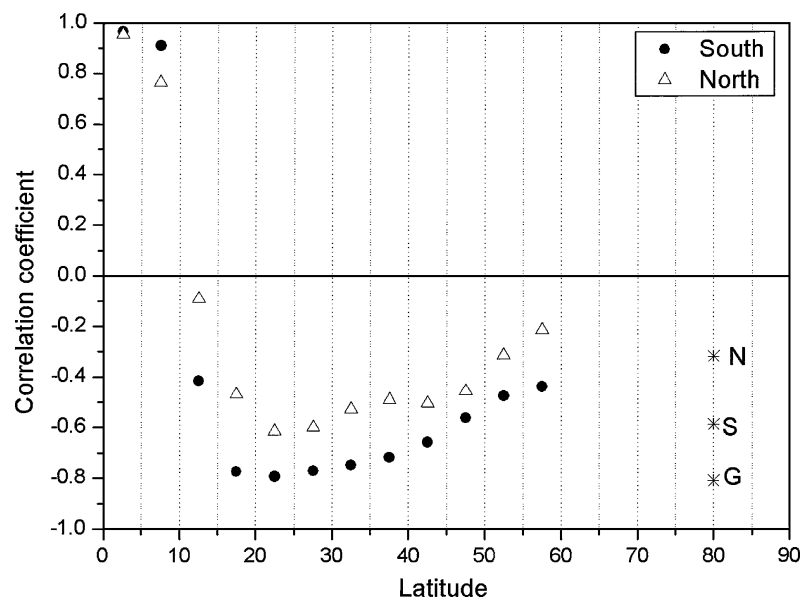

Fig 3. Linear fit correlation coefficients between ozone and ZWI (open triangles for Northern Hemisphere and full circles for Southern Hemisphere). The correlations for the globe (G) and for the Northern $(\mathrm{N})$ and Southern $(\mathrm{S})$ Hemispheres are also indicated to the side by asterisks $(*)$.

(1998) have found only a negative lag for most of the latitudinal bands in both hemispheres, of around -12 months, very close to the phase difference of around \pm 15 months found in this work. Thus, it can be concluded only that both hemispheric ozone signals are out of phase with the equatorial cycle by half a cycle, i.e. that extratropical ozone QBO variation is anticorrelated to the equatorial ozone variation.

Regarding phase changes with latitude, the transition from an in-phase variation at equatorial latitudes to an out-of-phase variation at mid-latitudes is well known to occur abruptly, in the $10^{\circ}-15^{\circ}$ zone (Zerefos et al., 1992; Yang and Tung, 1995; Kane et al., 1998). Hasebe (1980) found a phase reversal between $10^{\circ}$ and $47^{\circ} \mathrm{N}$. Hasebe (1983) and Zerefos et al. (1992) reported phase propagation from the northern and southern midlatitudes. Bowman (1989) reported phase shifts in correlations occurring around $50^{\circ} \mathrm{N}$ and $60^{\circ} \mathrm{S}$. Zerefos et al. (1992) have also found, from a limited Dobson data set, that the phase of the ZWI with ozone was linearly varying with latitude. Yang and Tung (1995) reexamined ground-based and satellite data in detail and concluded there were three distinct regions, tropical, mid-latitudinal and polar, in each of which the phase was fairly constant, and large phase shifts occurred only in the transition regions. Kane et al. (1998) have found, besides the transition region in the $15^{\circ}-20^{\circ}$ band, a phase shift between $45^{\circ}-55^{\circ} \mathrm{N}$ to $55^{\circ}-65^{\circ} \mathrm{N}$ from -12 to +6 months. From the results of previous and current work, it is possible to delineate the phase structure of the ZWI and ozone QBO signals: variation in phase at the $\pm 10^{\circ}$ equatorial zone, a transition zone with low correlation around $15^{\circ}-20^{\circ}$, and a zone with constant phase structure from $20^{\circ}$ to at least $50^{\circ}$, with a lag of about half a cycle (ozone variation anticorrelated to ZWI and equatorial ozone) in both hemispheres. There are indications of other phase transitions around $50^{\circ}-60^{\circ}$
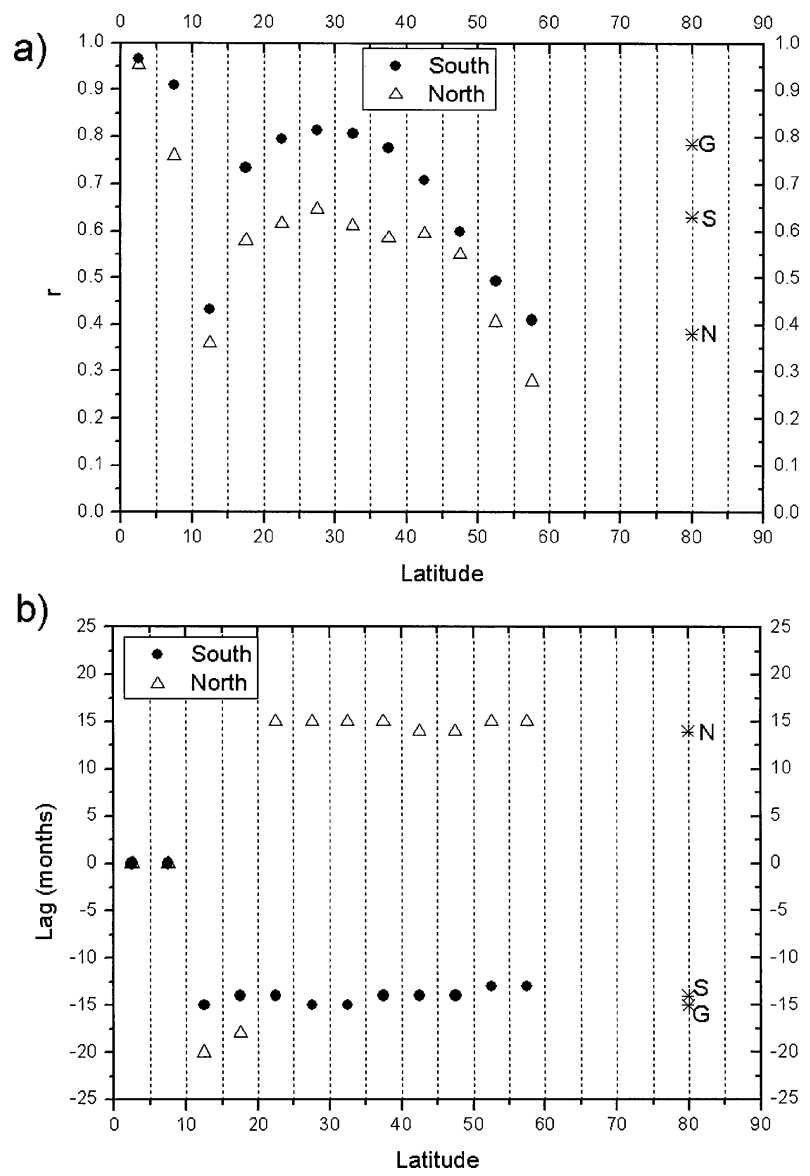

Fig 4. Cross-correlation coefficients (a) and lags (b) in months, between ZWI and ozone (open triangles for Northern Hemisphere and full circles for Southern Hemisphere) and ZWI. The correlations for the globe and for the Northern and Southern Hemisphere are also indicated to the side by asterisks $(*)$.

latitudes, but it is not possible to conclude on the existence of this transition ozone presently. Further studies encompassing the QBO signal in subpolar and polar ozone are necessary to assess the existence of this phase shift zone.

ARIST was applied to every $D_{4}$ decomposition level (shown in Figs. 1 and 2) and significant periodicities at 95\% confidence level were selected. Figure 5 shows an example of ARIST results for $50^{\circ}-55^{\circ} \mathrm{N}$ and $50^{\circ}-55^{\circ} \mathrm{S}$ latitudinal bands. Notice that the $\mathrm{D}_{4}$ levels for both bands have significant differences (Fig. 5a), with $50^{\circ}-55^{\circ} \mathrm{S}$ showing higher amplitude fluctuations, which is reflected in the spectral amplitudes found by ARIST (Fig. 5b). It can also be seen that fluctuations in both latitudinal bands are out of phase.

Figure 6 shows the spectral analysis of level $D_{4}$ signals in latitudinal bands. In the present analyses, only one periodicity was found in every latitudinal band $D_{4}$ level. Figure 6a shows the periods and Fig. $6 \mathrm{~b}$ shows the amplitudes (DU). Open triangles are for the Northern Hemisphere and full circles are for the 
Fig 5. Example of ARIST results to the $50^{\circ}-55^{\circ} \mathrm{N}$ and $50^{\circ}-55^{\circ} \mathrm{S}$ bands: (a) $\mathrm{D}_{4}$ levels; (b) spectrum (only one periodicity was found to be significant in each latitudinal band).
Fig 6. Spectrum analysis results of ozone level $D_{4}$ latitudinal bands using ARIST: (a) periods (yr); (b) amplitudes (DU). Open triangles are for the Northern Hemisphere and full circles for the Southern Hemisphere. Periods, amplitudes and phases for the globe (G) and for the Northern $(\mathrm{N})$ and Southern (S) Hemispheres are also indicated to the side by asterisks $(*)$. The solid line in the period panel indicates the ZWI values.
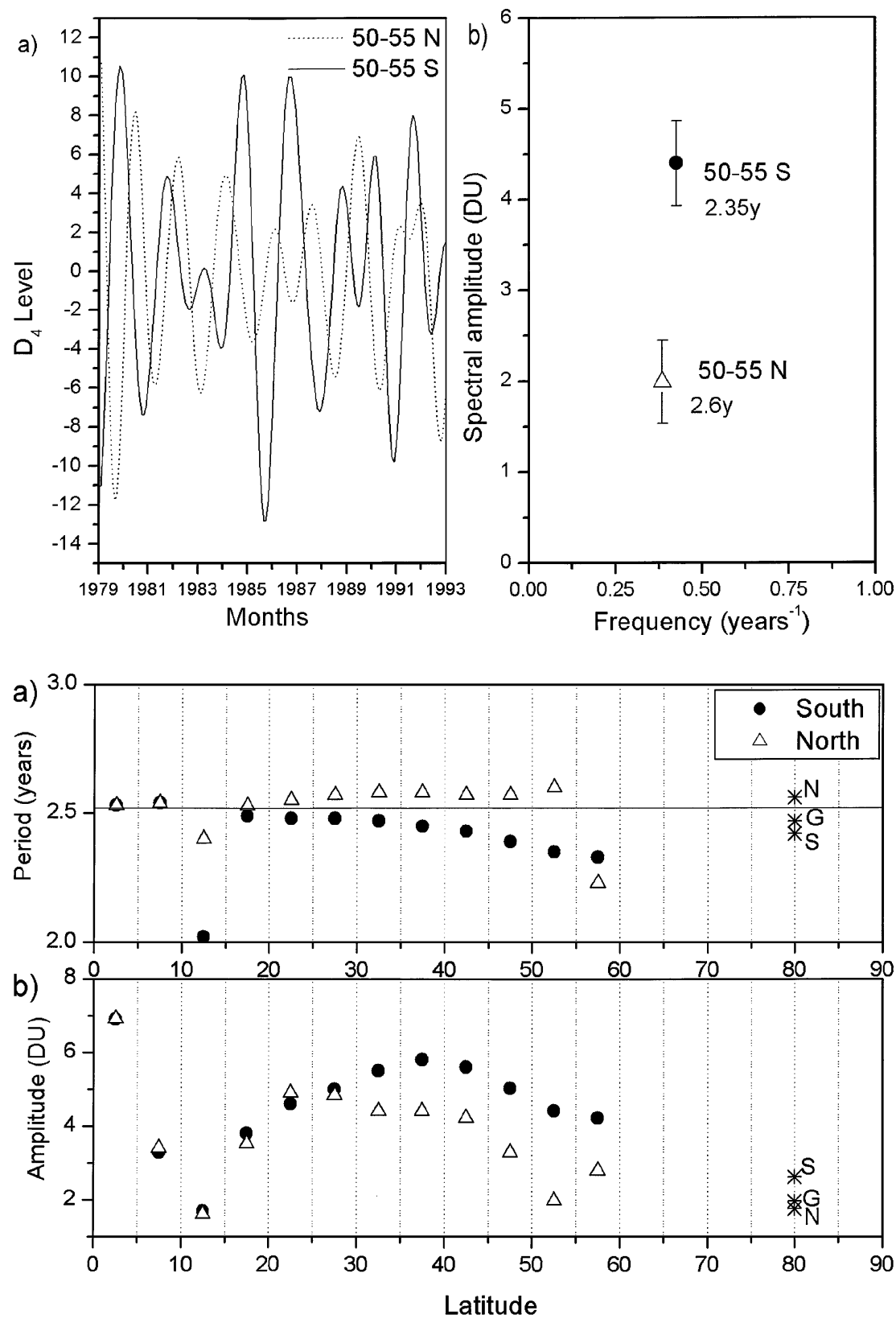

Southern Hemisphere. Periods and amplitudes for the globe and for the total Northern and Southern Hemispheres are also indicated by asterisks $(*)$. The solid line in the period panel indicates the ZWI values.

The period found for ZWI level $D_{4}$ is $2.52 \mathrm{yr}$, close to those found in the equatorial region for total ozone (2.53 and $2.54 \mathrm{yr}$ in $0^{\circ}-5^{\circ}$ and $5^{\circ}-10^{\circ}$ bands). Global, northern and southern total ozone periods are $2.47,2.56$ and $2.42 \mathrm{yr}$, respectively. The periods deviate significantly from the ZWI in the $10^{\circ}-15^{\circ}$ band and in bands higher than $40^{\circ}-45^{\circ} \mathrm{N}$ and $\mathrm{S}$. The latitudinal profile of the periods is different in the Northern and Southern Hemispheres. While in the equatorial region (latitudes lower than $10^{\circ}$ ) the ozone QBO period is close to the ZWI in both hemispheres, in the $10^{\circ}-15^{\circ}$ transition band the Northern Hemisphere ozone period is observed to be relatively close to the ZWI, but the Southern Hemisphere period is much lower (around $2 \mathrm{yr}$ ). In $15^{\circ}-20^{\circ}$, ozone periods are again close to the ZWI. However, from this region onwards, ozone periods tend to be increasingly different from the ZWI periods. In the Southern Hemisphere, the amplitude is higher, and periods are shorter than the ZWI. In the Northern Hemisphere, the amplitude is lower, but ozone periods are longer than the ZWI. A high fluctuation is seen in the northern $55^{\circ}-60^{\circ} \mathrm{N}$ band, with the ozone period becoming shorter than the ZWI instead of being longer. 
Kane et al. (1998) have also shown period profiles. They have observed an ozone QBO period close to the ZWI in the equatorial region, but in the transition region the ozone periods are not much different from the ZWI, in disagreement with the present analysis. In the Southern Hemisphere, they have found a trend of periods decreasing with latitude, similar to that obtained in this work. However, in the Northern Hemisphere they have found an oscillating profile, different from the quasi-monotonic increase with latitude found in this work. In their work, the ozone periods were higher than the ZWI period in $45^{\circ}-55^{\circ} \mathrm{N}$, but were lower than the ZWI in the band $\sim 60^{\circ} \mathrm{N}$, indicating an abrupt change in period, which was also observed in this work.

The amplitude of these periodicities (in DU) is found to be higher in the equatorial belt $0^{\circ}-5^{\circ}$, then decreases to a minimum in the $10^{\circ}-15^{\circ}$ band and increases again, reaching a maximum in the $35^{\circ}-40^{\circ}$ band in both hemispheres, then decreasing towards higher latitudes. Southern Hemisphere amplitudes are higher than those of the Northern Hemisphere. The results of Kane et al. (1998) for amplitudes are very close to those found in this work, with the Southern Hemisphere showing ozone amplitudes higher than the Northern Hemisphere, a main maximum in amplitude observed at equatorial region, decreasing to a minimum close to $15^{\circ}$, increasing again to a secondary maximum around $40^{\circ}$ and then decreasing again to higher latitudes in both hemispheres.

\section{Conclusions}

A detailed latitudinal profile of the QBO signal in total ozone was obtained in the present work, using wavelet multiresolution filtered total ozone and zonal wind data. Ozone was found to be nearly in phase with the QBO signal in this equatorial region $\left(0^{\circ}-5^{\circ}\right.$ and $\left.5^{\circ}-10^{\circ}\right)$, and to be out of phase (lag $\sim+15$ and -15 months in north and south) from $10^{\circ}-15^{\circ}$ to $55^{\circ}-60^{\circ}$ latitudinal ranges. The cross-correlation coefficient is high $(>0.7)$ at latitudes lower than $10^{\circ}$, decreases in the transition region $10^{\circ}-15^{\circ}$ $(r \sim 0.4)$ and has a non-linear profile to high latitudes, with a maximum around $25^{\circ}-30^{\circ}$. The correlation is observed to be higher for the Southern Hemisphere latitudinal bands. The same higher correlation for the Southern Hemisphere is obtained from simple (linear fit) correlations, but in this case correlation coefficients are negative after the $10^{\circ}-15^{\circ}$ latitudinal band. Spectral analysis was performed in each latitudinal range and the QBO period and amplitude profiles were obtained. The ozone QBO periods are longer than the ZWI in the Northern Hemisphere, and have a slight tendency to increase with latitude until an abrupt reduction of the period in the $55^{\circ}-60^{\circ} \mathrm{N}$ band. At this latitude, the ozone QBO period is shorter than the ZWI period. In the Southern Hemisphere, the ozone QBO period decreases monotonically (with the exception of the $10^{\circ}-15^{\circ}$ transition region) to values shorter than the ZWI period. Spectral amplitudes are high near the equator, decrease to a minimum in the $10^{\circ}-15^{\circ}$ range, increase again to a secondary maximum in the $35^{\circ}-40^{\circ}$ range, and finally decrease to high latitudes in both hemispheres.

\section{Acknowledgments}

The authors thank the TOMS processing team for ozone data and the Frei Universität Berlin for ZWI data. Thanks also go to the Brazilian government agency CAPES for a doctoral fellowship and to FAPESP (02/12723-2) for a post-doctorate fellowship.

\section{References}

Angell, J. K. and Korshover, J. 1973. Quasi-biennial and long-term fluctuations in total ozone. Mon. Wea. Rev. 101, 426-443.

Bowman, K. P. 1989. Global patterns of the quasi-biennial oscillations in total ozone. J. Atmos. Sci. 90, 7967-7976.

Echer, E. 2004. Multiresolution analysis of global total ozone column during 1979-1992 Nimbus-7 TOMS period. Ann. Geophys. 22, 14871493.

Funk, J. P. and Garnham, G. L. 1962. Australian ozone observations and a suggested 24-month cycle. Tellus 14, 378-382.

Gray, L. J. and Pyle, J. A. 1989. A two-dimensional model of the quasibiennial oscillation ozone. J. Atmos. Sci. 46, 203-220.

Hasebe, F. 1980. A global analysis of the fluctuation of total ozone: II. Non-stationary annual oscillation, quasi-biennial oscillation and longterm variation in total ozone. J. Meteorol. Soc. Japan 58, 104-117.

Hasebe, F. 1983. Interannual variations of global total ozone revealed from Nimbus 4 BUV and ground-based observations. J. Geophys. Res. 88, 6819-6834.

Hilsenrath, E. and Schlesinger, B. M. 1981. Total ozone seasonal and interannual variations derived from the 7 year Nimbus-4 dataset. $J$. Geophys. Res. 96, 7531-7545.

Hollandsworth, S. M., Bowman, K. P. and McPeters, R. D. 1995. Observational study of the quasi-biennial oscillation in ozone. J. Geophys. Res. 100, 7347-7361.

Holton, J. R. and Lindzen, R. S. 1972. An updated theory for the quasibiennial cycle of the tropical stratosphere. J. Atmos. Sci. 29, 10761080.

Kane, R. P., Sahai, Y. and Casiccia, C. 1998. Latitude dependence of the quasi-biennial oscillation and quasi-triennial oscillation characteristics of total ozone measured by TOMS. J. Geophys. Res. 103, 8477-8490.

Kumar, P. and Foufoula-Georgiou, E. 1997. Wavelet analysis for geophysical applications. Rev. Geophys. 35, 385-412.

Naujokat, B. 1986. An update of the observed quasi-biennial oscillation of the stratospheric winds over the tropics. J. Atmos. Sci. 17, 18731877.

Oltmans, S. J. and London, J. 1982. The quasi-biennial oscillation in atmospheric ozone. J. Geophys. Res. 87, 8981-8989.

Percival, D. B. and Walden, A. T. 2000. Wavelet Methods for Time Series Analysis, Cambridge University Press, Cambridge, 594 pp.

Plumb, R. A. and Bell, R. C. 1982. A model of the quasi-biennial oscillation on a equatorial beta-plane. Q. J. R. Meteorol. Soc. 108, 335352.

Reed, R. J., Campbell, W. J., Rasmussen, L. A. and Rogers, D. J. 1961. Evidence of a downward propagating annual wind reversal in the equatorial stratosphere. J. Geophys. Res. 66, 813-818. 
Rigozo, N. R. and Nordemann, D. J. R. 1998. Rev. Bras. Geofis. 16, 151-160.

Shepherd, T. G. 2000. The middle atmosphere. J. Atmos. Solar-Terr. Phys. 62, 1587-1601.

Stanford, J. L., Ziemke, J. R., McPeters, R. D., Krueger, A. J. and Bhartia, P. K. 1995. Spectral Analyses, Climatology and Interannual Variabilitiy of Nimbus-7 TOMS Version 6 Total Column Ozone. NASA Reference Publication 1360, NASA Scientific and Technical Information Branch.

Stolarski, R. S., Bloomfield, P. and McPeters, R. D. 1991. Total ozone trends deduced from Nimbus-7 TOMS data. Geophys. Res. Lett. 18, 1015-1018.

Tung, K. K. and Yang, H. 1994. Global QBO in circulation and ozone. Part I. reexamination of observational evidence. J. Atmos. Sci. 51, 2699-2707.
Veryard, R. G. and Ebdon, R. A. 1961. Fluctuations in tropical stratospheric winds. Meteorol. Mag. 90, 125-143.

Wolberg, J. R. 1967. Prediction Analysis, D. Van Nostrand, Princeton, NJ, $291 \mathrm{pp}$.

Yang, H. and Tung, K. K. 1995. On the phase propagation of extratropicla ozone quasi-biennial oscillaiton in observational data. J. Geophys. Res. 100, 9091-9100.

Zerefos, C. S., Bais, A. F., Ziomas, J. C. and Bojkov, R. D. 1992. On the relative importance of quasi-biennial oscillation and El Niño Southern Oscillation in the revised Dobson total ozone records. J. Geophys. Res. 97, $10135-10144$.

Zerefos, C. S., Tourpali, B., Isakien, I. S. A. and Schuurman, C. J. E. 2001. Long-term solar-induced variation in total ozone, stratospheric temperatures and the tropopause. Adv. Spa. Res. 27, 19431948. 